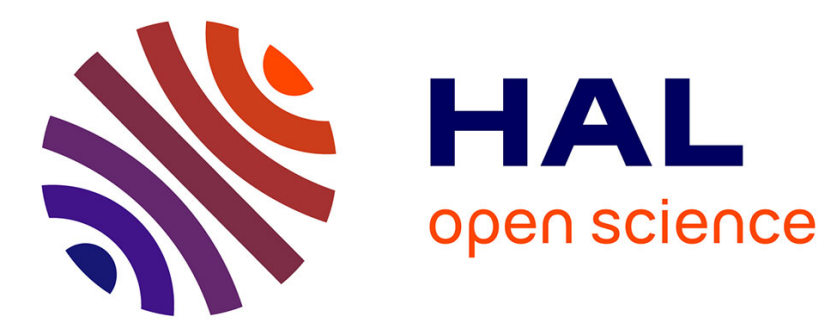

\title{
Multiwavelength micromirrors in the cuticle of scarab beetle Chrysina gloriosa
}

\author{
Gonzague Agez, Chloé Bayon, Michel Mitov
}

\section{To cite this version:}

Gonzague Agez, Chloé Bayon, Michel Mitov. Multiwavelength micromirrors in the cuticle of scarab beetle Chrysina gloriosa. Acta Biomaterialia, 2017, 48, pp.357 - 367. 10.1016/j.actbio.2016.11.033 . hal-01730490

\section{HAL Id: hal-01730490 \\ https://hal.science/hal-01730490}

Submitted on 8 Dec 2021

HAL is a multi-disciplinary open access archive for the deposit and dissemination of scientific research documents, whether they are published or not. The documents may come from teaching and research institutions in France or abroad, or from public or private research centers.
L'archive ouverte pluridisciplinaire HAL, est destinée au dépôt et à la diffusion de documents scientifiques de niveau recherche, publiés ou non, émanant des établissements d'enseignement et de recherche français ou étrangers, des laboratoires publics ou privés. 


\section{Multiwavelength micromirrors in the cuticle of scarab beetle}

\section{Chrysina gloriosa}

\section{Gonzague Agez, Chloé Bayon, Michel Mitov*}

Centre d'Elaboration de Matériaux et d'Etudes Structurales, CEMES, Centre National de la Recherche Scientifique, CNRS, UPR 8011, University Paul-Sabatier, F-31055 Toulouse cedex 4, France

*Corresponding author. E-mail address: mitov@cemes.fr

Keywords: Arthropod exoskeleton; Beetle cuticle; Chitin; Biological composite; Cholesteric liquid crystals; Structural color; Iridescence; Bio-inspiration; Electron microscopy; Modeling.

Article history: Received 6 September 2016 | Received in revised form 2 November 2016 | Accepted 13 November 2016 | Available online 14 November 2016.

https://doi.org/10.1016/j.actbio.2016.11.033

\section{ABSTRACT}

Beetles from the genus Chrysina show vivid reflections from bright green to metallic silvergold as a consequence of the cholesteric liquid crystal organization of chitin molecules. Particularly, the cuticle of Chrysina gloriosa exhibits green and silver stripes. By combining confocal microscopy and spectrophotometry, scanning electron microscopy and numerical simulations, the relationship between the reflectance and the structural parameters for both stripes at the micro- and nanoscales are established. Over the visible and near IR spectra, polygonal cells in tessellated green stripes behave as multiwavelength selective micro-mirrors 
and the silver stripes as specular broadband mirrors. Thermoregulation, conspecifics or intraspecies communication, or camouflage against predators are discussed as possible functions. As a prerequisite to bio-inspired artificial replicas, the physical characteristics of the polygonal texture in Chrysina gloriosa cuticle are compared to their equivalents in synthetic cholesteric oligomers and their fundamental differences are ascertained. It is shown that the cuticle has concave cells whereas the artificial films have convex cells, contrary to expectation and assumption in the literature. The present results may provide inspiration for fabricating multiwavelength selective micromirrors or spatial wavelength-specific light modulators.

\section{Introduction}

\subsection{Arthropod cuticles as multifunctional materials}

Arthropod cuticles serve a number of fundamental functions; the exoskeletons support the body, resist mechanical loads, provide environmental protection and resistance to desiccation [1-3]. Beyond these basic functions, the cuticles can also generate optical information with vivid structural colors [4] or chemical information [5]. These more advanced biological functions are of paramount importance in living organisms and understanding their physical properties will inform the creation of novel synthetic functional materials [6-11].

The cuticle of beetles is a composite material including chitin [1]. Owing to their chiral nature, chitin macromolecules may self-organize into a helicoidal structure and produce cholesteric liquid crystal (CLC) phase [12]. As a Bragg medium, the CLC phase may selectively reflect light; the reflection wavelength is directly proportional to the helicoidal 
pitch $[13,14]$. At normal incidence, the reflected light is circularly polarized in accordance with the helix, whereas the transmitted light is polarized with the opposite direction. This reflection of circularly polarized light by beetle cuticles appears to be restricted to Scarabaeidae, occurring predominantly in subfamilies Rutelinae, Scarabaeinae and Cetoniidae [15]. Several books and papers have reviewed the biological importance of iridescent colors in the insect world [4,16-19]. In comparison with pigment-based printing, structural colors like those of insect cuticles offer high brightness and saturation, lower cost, easier recycling, and higher reproduction fidelity and stability to applications in the following domains: security marking, information storage, high resolution and selectivity filtering, printing technologies, cosmetics, paints, coatings for vehicles, textile engineering [20].

\subsection{Background and literature review}

A great number of insects utilize tessellated exocuticles, containing arrays in the form of bumps, pits, or other physical variations. Some representative examples are given by: Manuka beetles [21], June beetles [22], Plusiotis boucardi [23], Pyronata festiva [24], Chlorophila obscuripennis [25], several tiger beetles of the genus Cicindela [15,26], Calidea panaethiopica [27], Chrysochroa fulgidissima [28], Chrysina aurora [29] or Anomala dimidata [30]. The cuticle of these animals constitutes a remarkable example of evolution providing a solution to conflicting requests, such as the selectivity of light reflection in a narrow wavelength band and diffusion over a wide angular range.

"Jewel scarabs", beetles from the genus Chrysina, exhibit vivid light reflection in a variety of colors from bright green to metallic silver-gold, indicating both selective and broadband reflection [31-34]. One of the most spectacular Chrysina species is C. gloriosa (Figure 1a), which can be found from southwestern North America to Central America in pine, pine-oak 
and juniper forests. C. gloriosa cuticle reflects left-handed circularly polarized light. It includes green and silver stripes which alternate (Figure 1b). This patterning is well-matched to the habitat of $C$. gloriosa, as the foliage of the juniper tree is green with white resin flecks [35]. The green stripes feature a polygonal texture which can be observed in bright field unpolarized microscopy (Figure 1c). Each polygonal cell contains a bright yellow core with orange edges surrounded by a dark-green region, with a brighter green rim delimiting the cells.
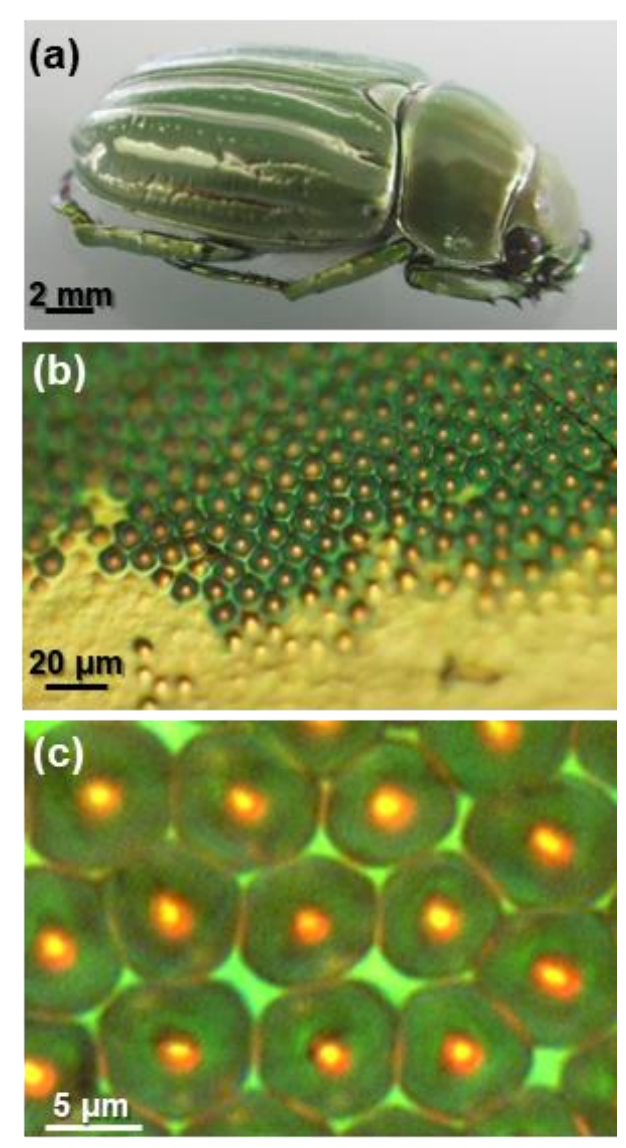

Fig. 1. (a) Chrysina gloriosa beetle (this dry specimen was used in this study). (b) Interface between green and silver stripes (reflection mode, bright field, unpolarized light). Although the transition between stripes is sharp, a few partially formed polygons are dispersed in the 
Accepted version in: Acta Biomaterialia 2017, 48, 357-367.

silver stripe at the close neighboring of the green one. Focusing the image across the entire surface is not possible because the cuticle is curved. (c) Magnified view of a set of polygons.

Previous research into the optical properties of the C. gloriosa cuticle includes:

(i) In 1972, Pace et al. examined the cellular structure of concentric rings in the green stripes, including cross-sectional views, via transmission electron microscopy (TEM). From these observations, a lens-like structure was suggested [36], comparable to the patterns, discovered by Bouligand, in the tubercle of crabs [37].

(ii) The reflectance exhibits, at normal incidence, a broad halo from 500 to $600 \mathrm{~nm}$ with two peaks at $530 \mathrm{~nm}$ (green) and $580 \mathrm{~nm}$ (yellow) [31].

(iii) In 2009, Sharma et al. confirmed the polygonal patterns with concentric rings by fluorescence confocal microscopy [38].

(iv) Fernandez del Rio et al. investigated the polarizing properties of the cuticle by using Mueller-matrix spectroscopic ellipsometry [39,40]. The reflectance was studied under illumination with various polarizations and the dependence of the polarizing properties of the cuticle with the polarization sensitivity of the detector was also characterized [40]. The roughness of the green stripe surface was determined to be the source of light scattering [39].

\subsection{Objectives of the study}

As a prerequisite to producing bio-inspired artificial replicas from C. gloriosa cuticle, a detailed understanding of structural regularities and irregularities in the cuticle at the nanoscale and, concomitantly, the related optical response is essential. Although the cholesteric texture in the cuticle plane $[36,38]$ or transversely $[36,38,39]$, and the polarization 
properties of the cuticle surface $[39,40]$ have been investigated, limited knowledge on all the structural and optical parameters necessary for determining the optical response and its origin is available and only phenomenological arguments have been given in literature. The relationship between reflectance and the structural parameters in the bulk of the material, i.e. pitch distribution and orientation of the helicoidal axis; the reflective properties of polygonal cells at multiple scales-from $25 \mu \mathrm{m}$ for a set of four cells down to submicronic areas in the inner core of a single cell; the spatial distribution of cell reflectance with wavelength; its relationship to the cholesteric periodicity as measured in cross-sections observed by scanning electron microscopy (SEM); and its correlation to the simulated optical response of the distinct cuticle areas have not been reported. Besides, in the context of artificial replicas, we show that the polygonal cells, structurally and optically, are not equivalent to focal conic domains found in open synthetic cholesteric films as it is believed in literature: the cuticle has concave cells whereas the artificial films have convex cells.

\section{Materials and methods}

\section{1. Sample}

The analyzed areas of Chrysina gloriosa cuticle specimen correspond to the elytra (wing covers). A cuticle sample, including green and silver stripes, was removed by using a razor blade. A diamond knife of an ultramicrotome (UltraCut S from Reichert) was then used at room temperature to cut the sample in a transverse direction by aiming for a smooth surface.

\subsection{Optical micrographs}


Details of the elytral surface were photographed with an Olympus BX51 stereomicroscope equipped with an Olympus DP73 digital camera.

\subsection{SEM}

JSM-6490 Scanning electron microscope from JEOL was used (secondary electron imaging mode at $20 \mathrm{kV}$ under normal conditions).

\subsection{TEM}

TEM investigations were performed using a Philips CM30 microscope operating at $300 \mathrm{kV}$ under normal conditions. This means that the dose of electrons received by the specimen is higher than the critical dose, deleting the diffraction contrast, so the images are produced by thickness diffusion contrast subsequent to irradiation. The contrast was enhanced by means of a slight defocusing [41-43].

\subsection{Reflectance mapping}

We used a spectrometer equipped with a standard confocal microscope (XploRA from Horiba) to scan an area of four adjacent polygonal cells. The reflectance baseline was realized by using a flat silver mirror located at the conjugate focal plane of the detector pinhole. $35 \%$ of reflectance in the scale bar means the intensity of the light reflected by the structure was $35 \%$ of the light reflected by a flat silver mirror. The reflectance spectrum was recorded at every point of the area with a step of $0.5 \mu \mathrm{m}$. An XY map contains $49 \mathrm{x} 49$ pixels so the scanning area of a map is $24 \times 24 \mu \mathrm{m}^{2}$. One $\mathrm{XY}$ reflectance map is related to 2400 reflection spectra. The acquisition was made with a x50 objective: one pixel of the XY map integrated information inside a voxel (volumetric element) with $0.5 \times 0.5 \times 2 \mu \mathrm{m}^{3}$ dimensions.

\subsection{Simulations methods}


To demonstrate the basic role of the cholesteric Bragg grating with variable periodicity from visible to NIR on the wavelength-tunability of a micromirror, numerical simulations were performed by taking into account the Bragg modulation of the index. Pitch gradient, distribution of the orientation of the helicoidal axis, spatial resolution and optical indices matched the experimental features. Simulations were performed by using the finite-difference time-domain (FDTD) method of the Meep software package [44]. This electromagnetic simulation software uses Maxwell's equations and were run over time within a finite computational region. Computational modeling by the FDTD method provides an accurate prediction of the optical response in structure-gradient LC structures [45]. The topic of complex pitch gradients present in beetle cuticles was recently addressed by Aguilar Gutierrez et al. via a geometric model and a computational visualization tool $[46,47]$. The computational grid resolution was 40 pixels per $\mu \mathrm{m}$. The $2 \mathrm{D}$ box size is 1200 pixels along the direction of light propagation and 800 pixels along the transverse direction, corresponding to two adjacent polygons. We imposed absorbing boundary conditions (the present approach utilizes a setup where the computational cell is surrounded with a medium that absorbs light without any reflection). We set the ordinary and extraordinary indices to 1.59 and 1.68 from data published by Caveney [48]. Since propagative and contra-propagative waves interfere, it was challenging to separate incident and reflected waves. To overcome this problem, light pulses were used. The incident wave was not monochromatic; a Gaussian beam as a wave train was used. The polarization was linear and orthogonal to the $\mathrm{XZ}$ plane. After a transient regime, 400 images of the electric-field energy density $E^{*} . \mathrm{D} / 2$ were recorded during 200 periods. The energy density from both the forward and backward (due to Bragg reflection) fields were recorded. This quantity oscillates with a pulsation equal to $2 \omega$. The color scale is proportional to the intensity. 


\section{Experimental results}

\subsection{Cuticle structure}

The cuticle of insects consists of three layers (from the exterior, inwards): the epicuticle (thin and transparent waxy layer), the exocuticle and the endocuticle. The critical cholesteric organization of chitin molecules is present in both the exo- and endocuticle. The SEM investigation of cross-sections of $C$. gloriosa cuticle demonstrates the typical cholesteric fingerprint texture, with alternate dark and bright lines (Figure 2). The helicoidal axis is perpendicular to the lines and the distance between two consecutive lines of equal contrast is related to the half-pitch of the helices.

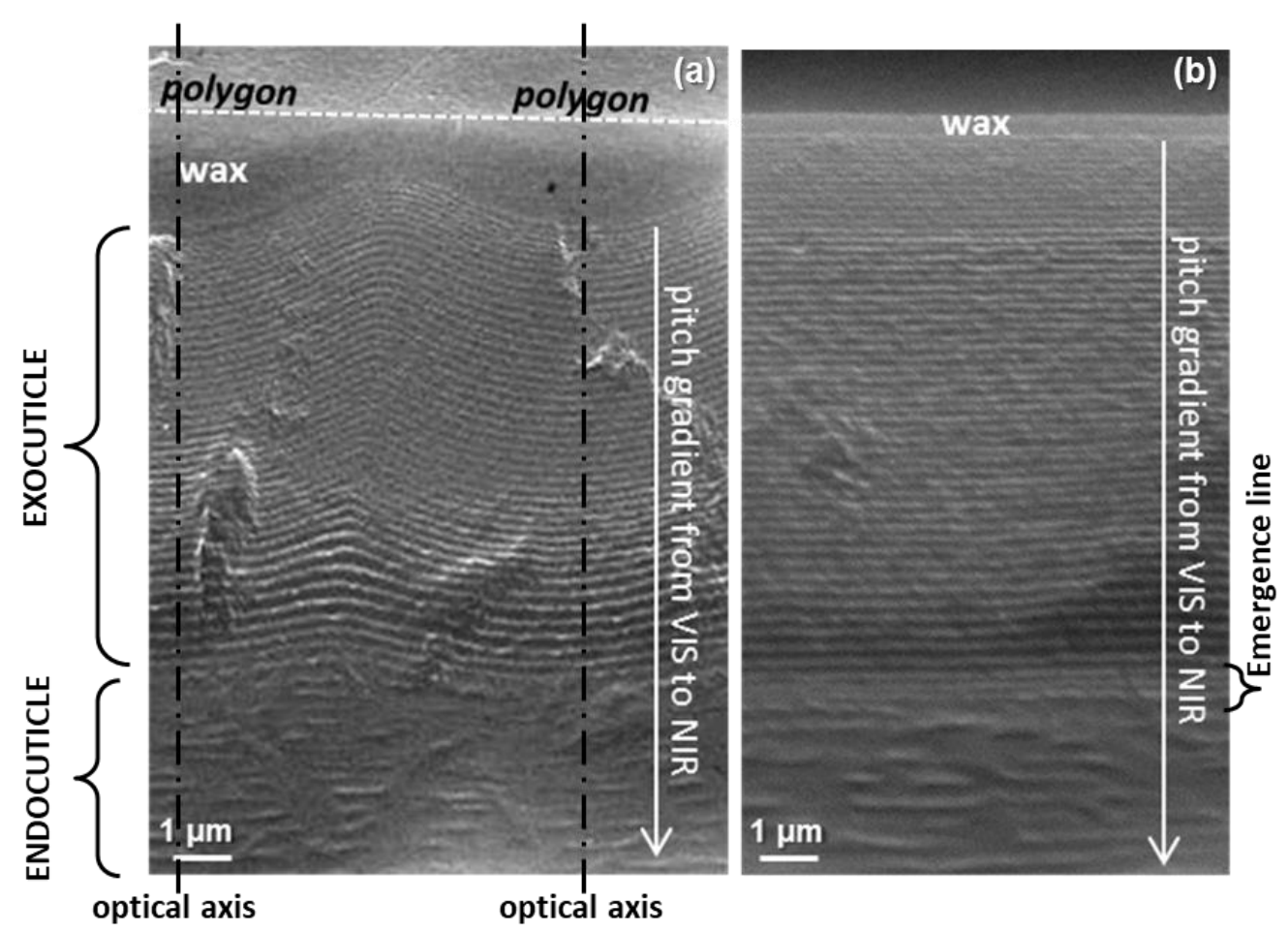

Fig. 2. SEM images of cross-sections in (a) green and (b) silver stripes. In a green stripe and below each polygon, as seen in Figure 1c, the fingerprint texture presents concave nested arcs or lines; the optical axis intersects the surface polygon in its center. In contrast, the lines 
are regularly parallel in a silver stripe. The lines correspond to cholesteric pseudo-layers [50]. The distance between two consecutive lines of equal contrast is related to the helicoidal pitch, while the helicoidal axis is perpendicular to the lines. The formation of the exocuticle and endocuticle is usually separated in time by moulting and is recorded structurally as the emergence line.

\subsubsection{Green stripe}

Inside a green stripe, the fingerprint texture stands as a network of nested arcs in the exocuticle (Figure 2a). This demonstrates that, inside a polygonal cell, the orientation of the helicoidal axis is not constant but, in fact, changing between regions. The curvature of the lines is attenuated in the lowest part of the exocuticle and progressively disappears in the endocuticle. The fingerprint texture in the endocuticle appears as less regular (lines are interrupted) and grainy, similar to the texture observed in the endocuticle of Homarus americanus [49]. The endocuticle of arthropods is often characterized by a much coarser texture. This texture change, related to a change in the stacking density of cholesteric pseudolayers [50], is accompanied by an abrupt mechanical discontinuity; in the endocuticle, both stiffness and hardness are much smaller than in the exocuticle [49]. 


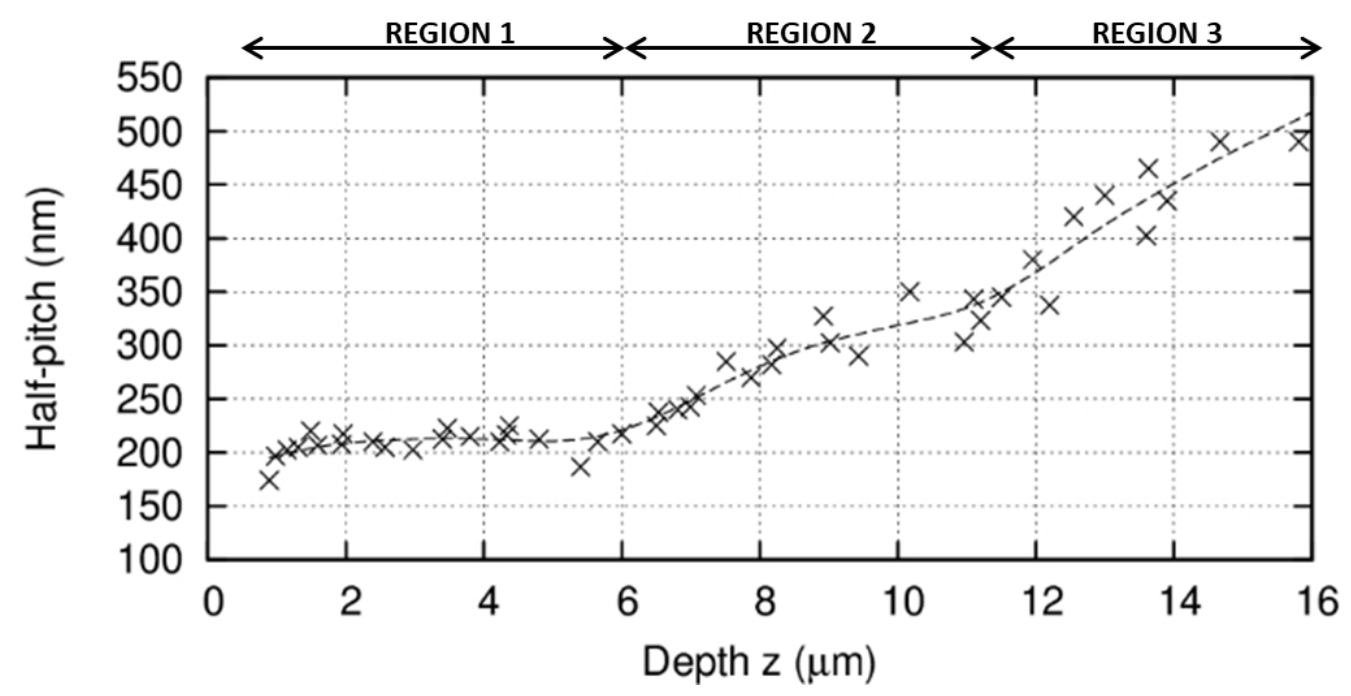

Fig. 3. Periodicity (half-pitch) in the fingerprint texture of a green stripe (like in Figure 2a) as a function of the $z$ depth along the optical axis.

The cholesteric structure presents an increasing pitch from the exo- to the endocuticle. The fingerprint texture exhibits a non-monotonic profile with three distinct regions (Figure 3) as measured along the optical axis marked in in Figure 2a. Each region is associated with a specific optical response: $(i)$ the exocuticle consists of a quasi-constant pitch $(\sim 400 \mathrm{~nm})$ to a depth of $6 \mu \mathrm{m}$, followed by (ii) a slight pitch variation from 400 to $700 \mathrm{~nm}$ to a depth of 10 $11 \mu \mathrm{m}$, structurally producing color in the visible spectrum; (iii) a more drastic pitch increase, from 700 to $1100 \mathrm{~nm}$, relating to the end of the visible and into the near IR (NIR) spectrum, is observed in the endocuticle, deeper than $11 \mu \mathrm{m}$ from the surface. Diffuse reflectance—when an incident ray is reflected at many angles, rather than at one angle as in the case of specular reflection - arises in green stripes from a combination of this continuous pitch gradient, with the irregularity of the polygon-studded exocuticle surface below the flat transparent wax layer. The angle-independent selective wavelength reflectance of $C$. gloriosa arises from these irregularities in the cholesteric region of the cuticle, in contrast to the single-pitch or graded- 
pitch cholesteric iridescent reflectors found in some insect cuticles where the reflected color changes with the viewing angle. Reflecting a consistent green color and intensity independently of viewing angle may presumably enhance the camouflage function in green foliage.

In the endocuticle, a cholesteric grating with a large-pitch gradient (lowest part in Figure 2a) might serve to avoid overheating. Such thermoregulation seems to be offered to many arthropods - insects and beach-dwelling crabs — whose cuticle exhibits a pitch gradient in the IR range [51]. Dorsal coloration has consequences for thermoregulation in diurnal beetles; niche differentiation associated with thermoregulation is documented in tiger beetles in Ref. [52] and references therein.

In summary, the green stripe consists of a reflector in the exocuticle to display information — color, polarization [39,40] — in the visible spectrum, and a NIR reflector in the endocuticle supposed to regulate temperature. To manage electromagnetic interactions between the body of the arthropods (cuticle or wings) and the outer world, nature has developed structures adapted to different requirements. It is interesting to draw a parallel between the present cuticle structure and the structure found in chameleon skin [53], by keeping in mind that this parallel has obviously strong limitations since both "coverings" have huge differences in chemical composition and structure. Chameleons have two superimposed populations of iridophores with different morphologies and functions: the upper multilayer is responsible for structural color change through the tuning of nanocrystal spacing in a triangular lattice, whereas the deeper population of cells broadly reflects light in the NIR range. This combination allows some species of chameleons to exhibit dramatic camouflage while moderating the thermal consequences of solar radiation. The combined presence of both 
reflecting structural elements and mobile absorbing pigments likely allows chameleons to adjust their body temperature in a larger set of conditions than if only pigments or photonic crystals were present.

\subsubsection{Silver stripe}

The exocuticle in the silver stripes is characterized by pitch increasing with depth (Figure 2b). However, in a singular region at the junction between the exo- and the endocuticle, the pitch is clearly smaller. Such a peculiar region was observed in the cuticle of the insect Tenebrio and reported as the emergence line [54]. The formation of the exocuticle and endocuticle is usually separated in time by ecdysis (moulting), recorded structurally as the emergence line [55]. Silver stripes are essentially chirped mirrors, i.e. broadband reflectors. Because the reflected light is directional (i.e. parallel incoming light is reflected into parallel rays), and not scattered, specular reflection is produced, and a metallic appearance with a mirror finish is the result. In silver metallic beetles, the reflector often reflects a broader spectrum than the visible; the human eye is therefore not capable of detecting iridescence.

The bright glare from silver stripes might temporarily blind a potential predator, enabling C. gloriosa beetle to escape [56]. It has been postulated that the mirror-like nature of the exocuticle could enable a beetle to match whatever environment it finds itself in; the shiny surface would mirror the green color of its environment and, during the dry season, the beetle could hide among the same leaves when they are brown [56]. However, this hypothesis has been disputed by other authors who emphasize that gold and silver species are also found in evergreen tropical cloud forests, indicating separate evolutionary driving forces [35].

While the cholesteric gratings of both the green and the silver stripes are of comparable scales, the presence of the polygonal patterning in the green stripes serves as an important 
differentiator. The pitch variations are not strictly superimposable, as it will be shown below, because the pitch has to adapt to the curvature of pseudo-layers in a green stripe. The tessellated surface texture in green stripes contrasts with the flatness of specular reflection in silver stripes and as well as imparts an angle distribution relative to the orientation of the helicoidal axis.

\subsection{Mapping of light reflection in green stripes}

This section presents a local and wavelength-dependent analysis of cholesteric reflections by the tessellated cuticle (Figure 4). An area of four polygonal cells was analyzed via a spectrometer mounted to a confocal microscope (inset of Figure 4). The reflection maps of various wavelengths, from blue $(475 \mathrm{~nm})$ to NIR $(975 \mathrm{~nm})$, with a narrow wavelength increment of $25 \mathrm{~nm}$ is shown. The microscope focus was set to the surface, i.e. the air-wax interface. Intense reflections occur along the sides of the polygons and manifest as donut-like patterns from [475-500] $\mathrm{nm}$ to [525-550] nm; this illustrates why the sides of polygons appear green in the optical image (Figure 1c or inset of Figure 4). The donuts extinguish in the 550$575 \mathrm{~nm}$ map. After transitional patterns into the next three spectral regions, a bright central spot-at the intersection between the focus plane and the optical axis as marked in Figure $2 \mathrm{a}$-appears in the $650-675 \mathrm{~nm}$ range. This spot corresponds to the polygon center and the reflection intensifies into the next two channels, up to $725 \mathrm{~nm}$. The yellow (respectively red) part of the visible spectrum is selectively reflected by the center (respectively sides) of polygons, which explains why a yellow spot with an orange-red contour is visible in the optical image. The reflection of these spots then decreases from the 725-750 nm range. After transitional patterns in between visible and NIR spectra, from 750 to $825 \mathrm{~nm}$, reflection patterns occurring in rims remain visible until the end of the investigation at $975 \mathrm{~nm}$. The 
main feature of this sequence (from $825 \mathrm{~nm}$ ) is that the reflection continuously increases as the spectrum moves into the NIR.
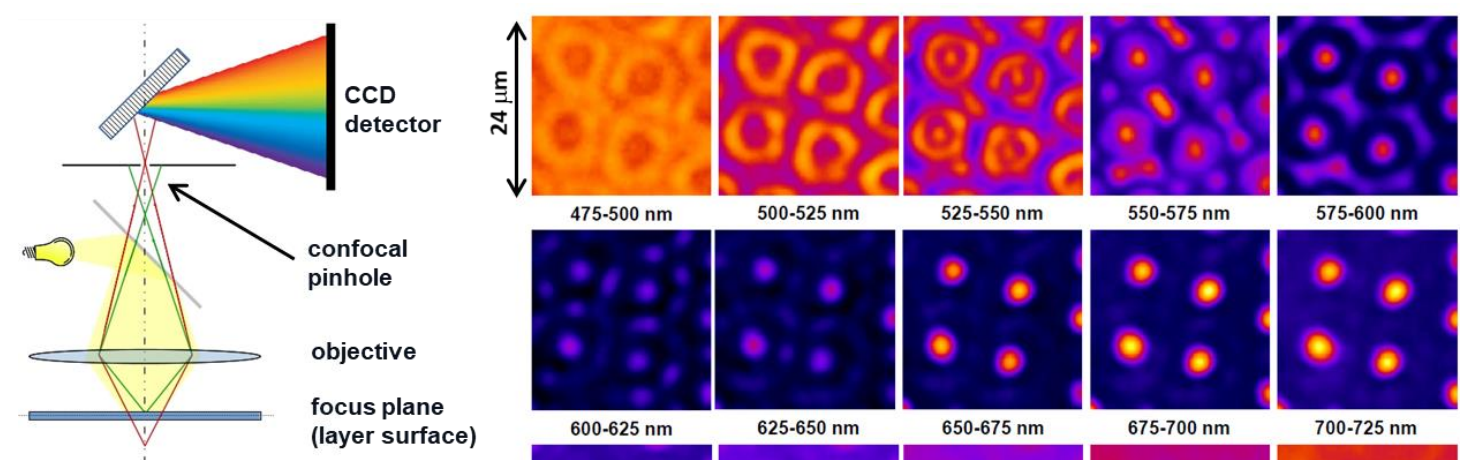

$600-625 \mathrm{~nm}$ $625-650 \mathrm{~nm}$ $650-675 \mathrm{~nm}$
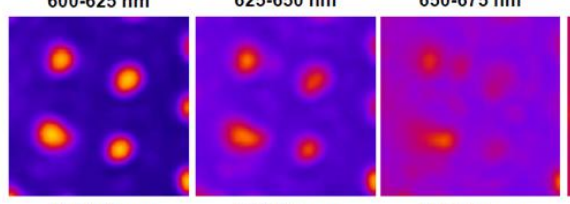

$675-700 \mathrm{~nm}$
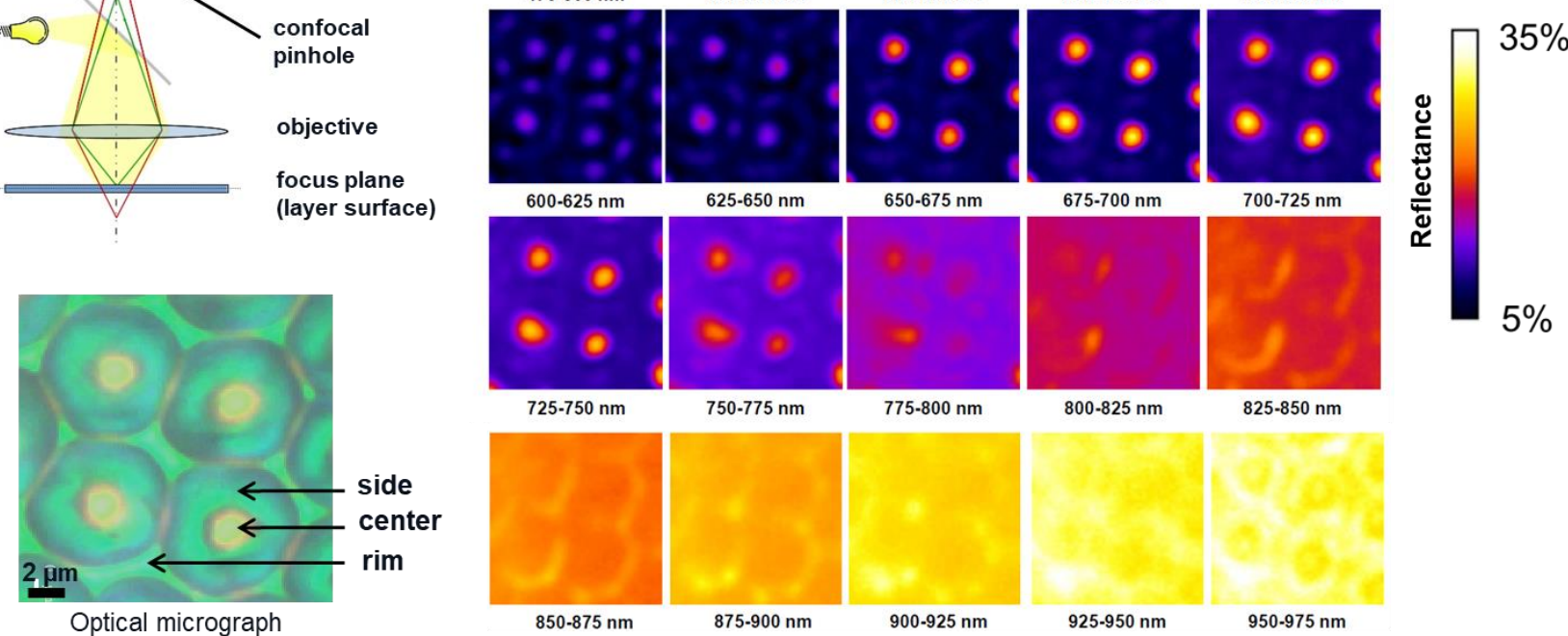

$750-775 \mathrm{~nm}$

$775-800 \mathrm{~nm}$
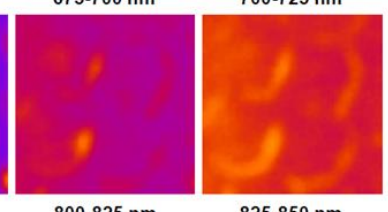

$800-825 \mathrm{~nm}$

$825-850 \mathrm{~nm}$

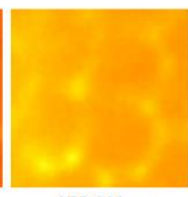

$875-900 \mathrm{~nm}$

$900-925 \mathrm{~nm}$

$925-950 \mathrm{~nm}$

$950-975 \mathrm{~nm}$

Fig. 4. (Top left:) The experimental setup: confocal microscope coupled to a spectrometer in reflection mode. (Bottom left:) Optical micrograph of a set of four polygons (reflection mode, bright field, unpolarized light). (Right:) Mapping of reflected intensity at the focus plane for twenty wavelength ranges. The scale bar depicts the 8-bit lookup table used for color representation in the range [5\%; $35 \%] .100 \%$ of reflection corresponds to a flat silver mirror.

In summary: $(i)$ the reflectance is spatially sensitive to wavelength changes, the highest levels of reflectance come from different parts of a polygon - from the sides in the lower (green) end of the visible spectrum and longer wavelengths (orange) from the center; (ii) in the NIR spectrum, from 825 to $975 \mathrm{~nm}$, the variation in reflectance consists of a mean level change weakly sensitive to the patterning. This result is consistent with the structure (Figure 
2a) since the cholesteric pseudo-layers in the endocuticle, which generate the NIR reflections, appear continuously parallel; the orientation of the helicoidal axis changes slightly and this deeper part of the cuticle is not sharply tessellated, and thus the reflection pattern is weakly structured. In $\$ 3.1 .1$, we suggested that the endocuticle served as a broadband reflector in the IR spectrum for possible thermoregulation purposes. Additionally, it would be worthwhile to further investigate if crepuscular and nocturnal insects, such as C. gloriosa [57], use NIR or IR wavelengths for navigation or intra-species communication [29]. Finally, many green insects show a high NIR reflectance close to that of their habitat foliage [58]; this property could be used by $C$. gloriosa beetles as camouflage against nocturnal predators capable of detecting IR light.

More generally, the wavelength-sensitivity of the reflection pattern-occurring essentially in the visible spectrum — would benefit from being related to the spectral sensitivity of eyes of C. gloriosa conspecifics as well as predators. For example, different species of Coleoptera are known to show mid-green wavelength sensitivity [59-61]. A link might exist between the reflection spectra and the peak sensitivities of the photoreceptors of conspecifics [23]. Alternatively, the wavelength-dependent patterns could simply be a by-product of light interaction with the chiral nested-arc network (Figure 2a).

\section{Numerical simulations}

To calculate the propagation of light across the cuticle, numerical replicas were generated. Based on the structures observed by SEM, the reflected light response was simulated using the FDTD (finite difference time domain) method and Meep software (see §2.6), and the results were compared to the experimental observations for green and silver stripes. 


\subsection{Green stripe}

A transverse graded-pitch grating (Figure 5), occurring in concave layers, was generated from the experimental image. The structure is illuminated with a plane wave Gaussian pulse (centered at $\lambda_{0}$ with a spectral width $\Delta \lambda_{0} / \lambda_{0}=0.1$ ); the reflected pulse propagating backward is isolated from the forward input beam.

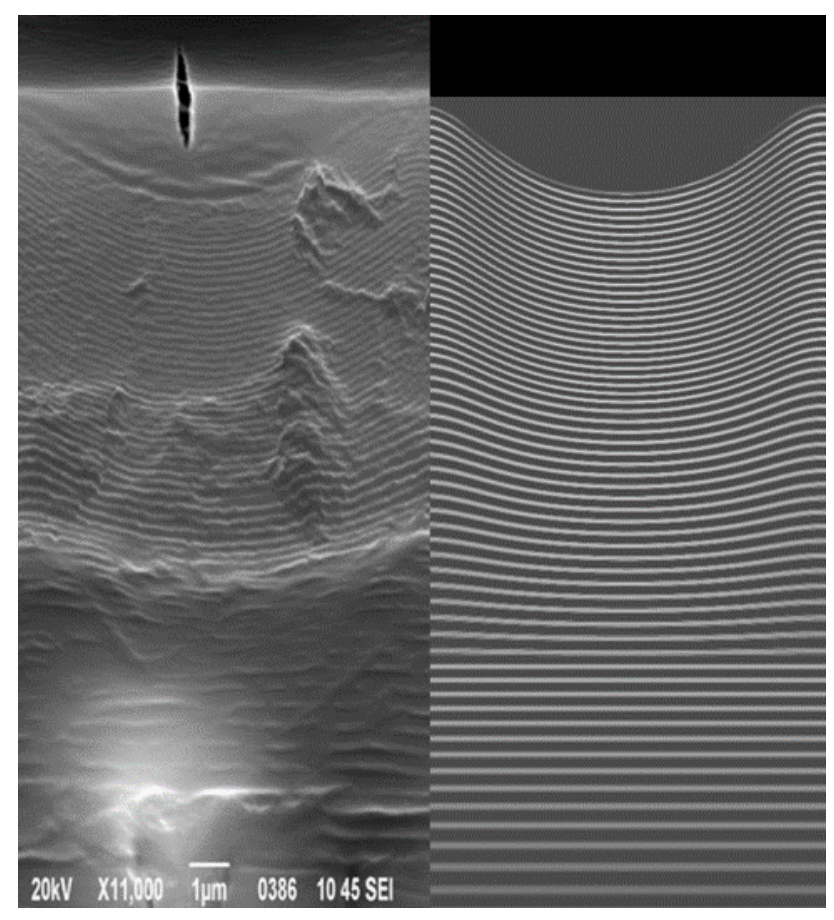

Fig. 5. Transverse network generated for numerical simulations in direct relation with the concrete structure. (In the SEM image, the irregularities correspond to the section facies of the sample. A crack is very often visible in the wax filling the concave cavity of the polygonal cell, but not for all the cells).

Simulated cross-sectional maps of light reflection, accompanied by experimental maps as charted in the cuticle plane, are displayed for four different incident wavelengths in Figure 6. 

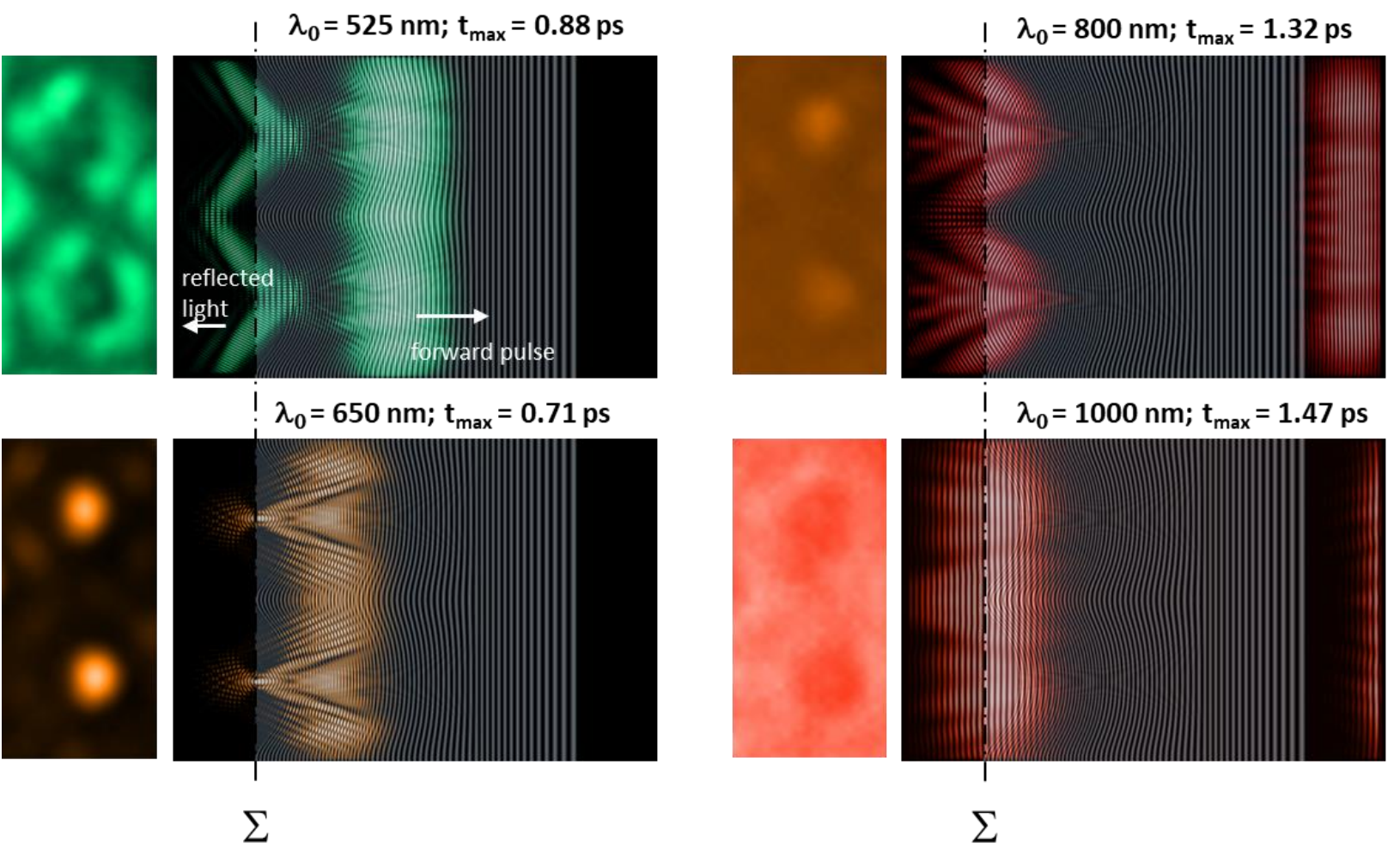

Fig. 6. Numerical simulations vs. experiment for four wavelengths. For each case is represented: (Left: ) the experimental reflection map in the plane of the cuticle ( $\Sigma$ plane), in view of (Right: ) the snapshot of the calculated energy density of the electric field in a transverse direction at time $t$ measuring the time elapsed since the pulse generation. The network generated for simulations is superimposed to the image for direct comparison with the structure.

For comparison purposes, the experimental image was situated in a plane perpendicular to the simulated view and through the imaging plane $\Sigma$. The simulated grating is superimposed onto the numerically calculated energy density of the electric field. When the wavelength of incident light is equal to $525,650,800$ and $1000 \mathrm{~nm}$, the basic patterns, donut, bright spot, diffuse spot and continuum background, respectively, found in Figure 4 are produced. The four images are snapshots at different times, $\mathrm{t}_{\max }$, chosen when the backward pulse intensity is 
maximum in the plane $\Sigma$. A small $t_{\max }$ means that the corresponding light is reflected by the pseudo-layers nearest to the surface and, consequently, the forward pulse has propagated over a shorter distance. Moreover, the lack of intensity in the forward pulse indicates which part the polygonal cell (center, side or rim) is responsible for the corresponding reflected light. The simulations show that the bright central spots at $650 \mathrm{~nm}$ are induced by the central part of the very first concave pseudo-layers of the exocuticle at quasi-normal incidence. In that spectral range, it is confirmed that the concave polygon behaves as a spherical micromirror. The donuts at $525 \mathrm{~nm}$ are produced by the sides with oblique incidence resulting in off-axis reflection with a spectral blue-shift. At $800 \mathrm{~nm}$, the diffuse spots are the consequence of a reflection by the lower part of the exocuticle whereas in the IR spectral range the flat structure of the endocuticle is responsible for the continuum background observed at $1000 \mathrm{~nm}$.

There is good agreement between the simulated and experimental maps, confirming the wavelength dependence of the diffuse reflectance and the distribution of the reflected light in the different parts of polygonal cells.

\subsection{White stripe}

Since the silver stripes are not patterned, it is relevant to describe their reflectance properties by using spectral, rather than spatial, maps. Figure 7a shows the variation of the periodicity (distance between two lines of same contrast, i.e. the half-pitch $p / 2$ ) with the $z$ depth in the cuticle thickness, and Figure $7 \mathrm{~b}$ shows the related SEM micrograph of the $16-\mu \mathrm{m}$ thick cuticle layer. The graph highlights the presence of a trough in the periodicity variation at $z \sim 11 \mu \mathrm{m}$. We allot this trough to the emergence line (see §3.1.2). Figures $7 \mathrm{c}$ and $7 \mathrm{e}$ are, respectively, the experimental and simulated reflection spectra when the trough is taken into account; the spectrum in Figure 7e was generated from the simulated grating in Figure $7 \mathrm{~d}$. 
The agreement between spectra is good, with broadband reflection occurring from 450 to $1000 \mathrm{~nm}$ and exhibiting ripples. The presence of a ripple structure superimposed onto a broadband plateau is also present in the spectrum of the cuticle of the Chrysina aurigans beetle $[29,62]$, where it was interpreted as the consequence of defects in the twisted structure. These defects are fluctuations in the azimuthal angle, specifying the orientation of the chitin fibrils at a depth $z$, modulating the reflection spectrum [62]. In the case of C. gloriosa, the site of defects is related to the emergence line. Ripples can be attributed to longitudinal interferences as a consequence of the existence of this singular region between exo- and endocuticles. To demonstrate, we simulated the reflection spectrum from a grating exhibiting a continuous pitch gradient without the trough (Figure 7f). The result (Figure 7g) shows a strong attenuation of ripples, and the agreement with the experimental spectrum (Figure 7c) is diminished.

Returning to the pitch variation in the green stripe (Figure 3): region 2 marks an interruption in the variation of increasing pitch and appears to be an intermediate variation; it falls in the thickness range in which the emergence line is expected and region 2 could correspond to the structural features of its presence. The morphology of the emergence line is different (not visible at first glance in Figure 2a vs. a group of few lines of smaller periodicity visible in Figure 2b) and the pitch variation is less abrupt (slow slope in Figure 3 vs. trough in Figure $7 a)$, as a consequence of the nested-arc structure. 
(a)

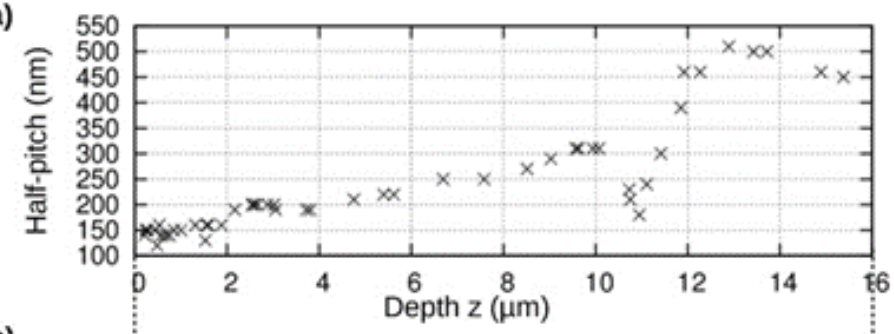

(b)

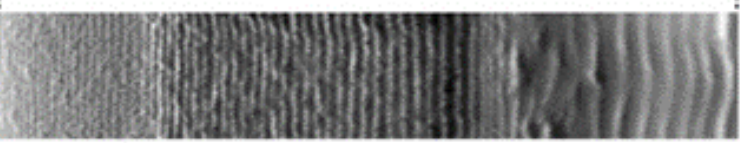

(c)

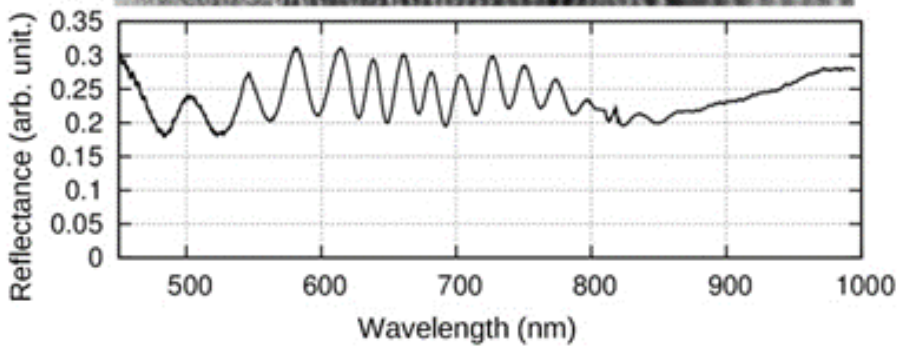

(d)

(e)
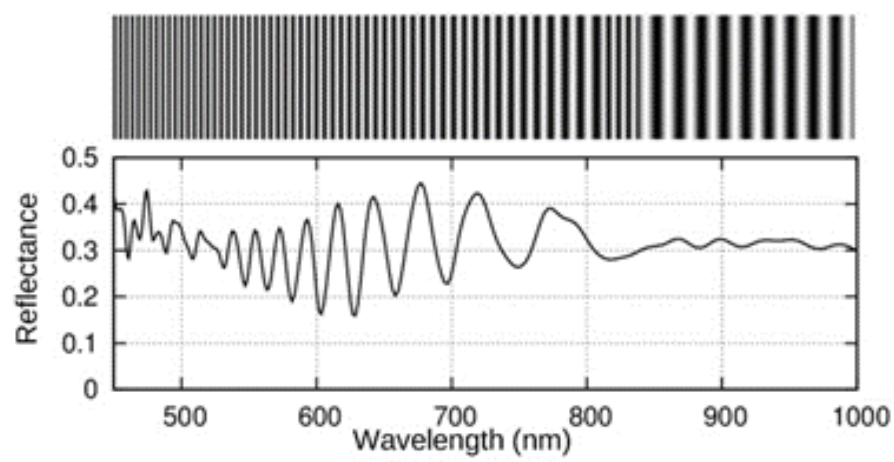

(f)

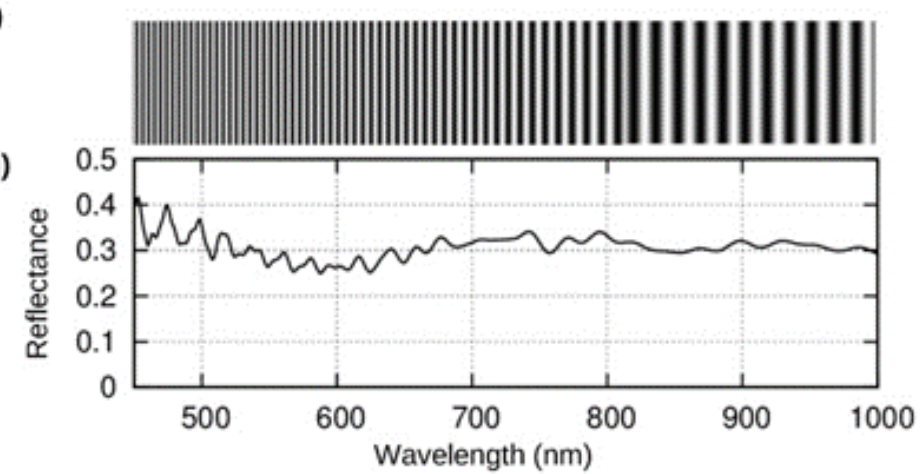

Fig. 7. Experimental and simulated reflection spectra in a silver stripe in relationship with the transverse periodicity (half-pitch). (a) Experimental periodicity as a function of the $z$ depth in the cuticle thickness. (b) SEM cross-sectional image related to the pitch variation shown in $a$. 
Accepted version in: Acta Biomaterialia 2017, 48, 357-367.

(c) Experimental spectrum. (d) Transverse network generated for simulations from a micrograph as shown in $b$ by keeping the trough occurring at $z \sim 11 \mu \mathrm{m}$. (e) Simulated spectrum related to $d$. (f) Transverse network generated for simulations from a micrograph as shown in $b$ by ignoring the trough, which means that a continuous pitch gradient is generated. (g) Simulated spectrum related to $f$.

\section{Comparison artificial vs. biological structures}

In the context of the fabrication of advanced functional materials inspired from C. gloriosa micromirrors, we compare the physical properties of polygonal textures as found in synthetic CLCs and the $C$. gloriosa cuticle in light of present results.

In 1972, Bouligand studied, via optical microscopy, the geometry and defects of polygonal textures found in mixtures of MBBA (methoxybenzylidene butylaniline; nematic LC) with cholesterol benzoate or Canada balsam as a chiral dopant [63]. More recent investigations have used oligomeric films to investigate polygonal textures by AFM (Atomic Force Microscopy) [64-73], TEM [67,68,70] and SEM [67]. These oligomers consisted of cyclic siloxane chains to which two types of side chains are attached via aliphatic spacers (achiral mesogen and chiral cholesterol-bearing mesogen) [74]. The CLC phase appeared between $180-210^{\circ} \mathrm{C}$ (clearing temperature range) and $40-50^{\circ} \mathrm{C}$ (glass-transition temperature range), with a helicoidal pitch of $370 \mathrm{~nm}$ and a left-handed structure. The mean position of the reflection band was $560 \mathrm{~nm}$ - centered inside the 500-600 nm range assigned to the green stripe of C. gloriosa cuticle [31]. More details, including the transmittance spectrum of the sample, are in Ref. [67]. 
In the present study, thin films of varying thickness were coated at $140^{\circ} \mathrm{C}$ onto a plain glass plate and covered with another glass plate. The upper plate was then removed after quenching, when the film had solidified. The spontaneous nucleation and growth of the polygonal texture from the air interface promptly occurred in the viscous state (at $140^{\circ} \mathrm{C}$ in our study) and gave rise to an array of polygons with various sizes as shown in Figure 8a. The material was then rapidly quenched to room temperature and the cholesteric organization, producing photonic properties, was stored inside a solid film. In 1996, Meister et al. showed, by TEM, that the nested arc patterns found close to the free surface in a single polygon cut in a direction oblique to the helicoidal axis [65]. In 2011, by combining SEM and TEM, Agez et al. provided the $3 \mathrm{D}$ representation of polygons with the required connections between polygons [67]. Figure $8 \mathrm{~b}$ shows a TEM image of neighboring polygons in a direction transverse to the film plane.
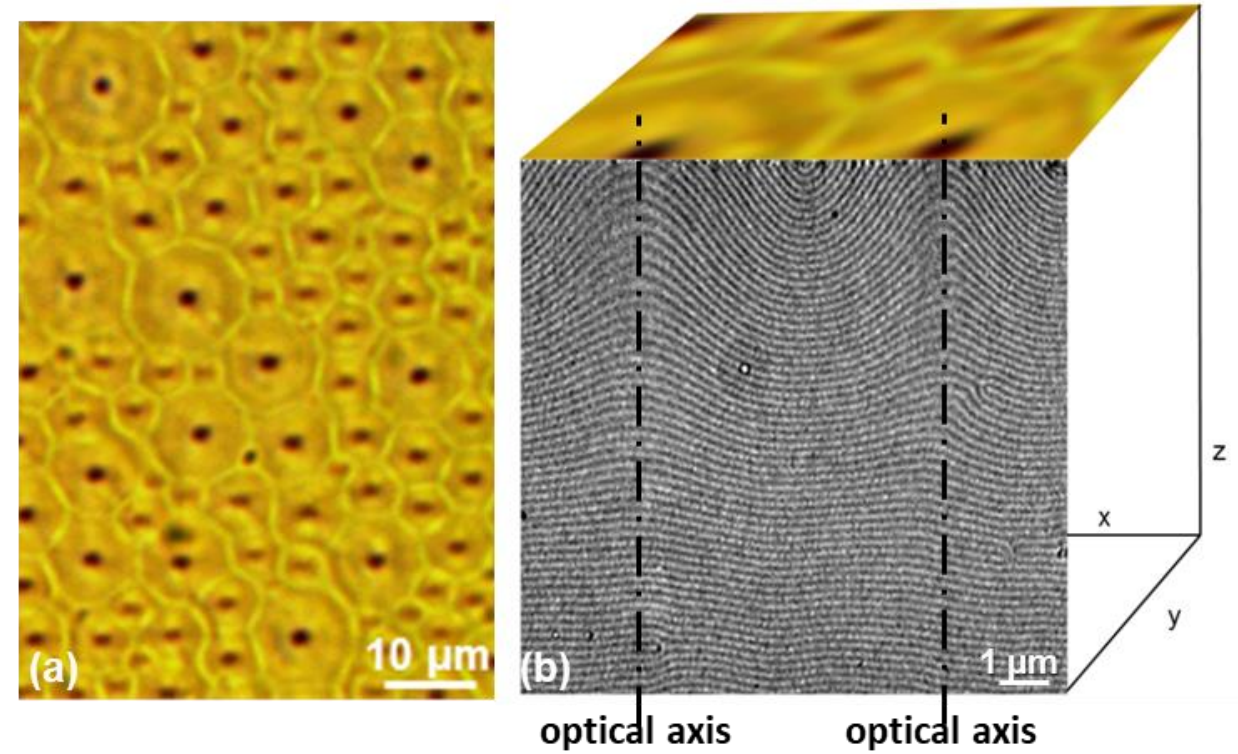

Fig. 8. Polygonal texture in a synthetic oligomer film. Thickness $=12.5 \mu \mathrm{m}$. Annealing time $=$ 13 hours. (a) Optical micrograph (transmission mode, bright field, unpolarized light). (b) TEM 
Accepted version in: Acta Biomaterialia 2017, 48, 357-367.

cross-sectional image corresponding to a couple of polygons. The air interface (respectively glass plate interface) is at the top (respectively bottom) of the image. The fingerprint texture presents convex nested arcs (or lines) below each polygon. A network of parallel lines appears deeper in the film thickness.

Sharma et al. [38] described the polygonal cells of C. gloriosa as completely analogous to the focal conic domains found in Ref. [65]. Agez et al. [67] and Bayon et al. [75] have mentioned analogies between the polygonal textures found in the C. gloriosa cuticle and in the same oligomer film. In fact, the present investigation highlights fundamental differences. (i) The most important differentiator is that the nested arced patterns inside a cholesteric polygon are convex for the synthetic film (Figure 8b), while they are concave for the biological material (Figure 2a). (ii) The cuticle surface is quite flat due to the presence of the wax layer which fills the pits in concave mirrors whereas the convex polygons in the synthetic film exhibits a small relief in the $20-100 \mathrm{~nm}$ range as shown by AFM [67]. (iii) The anchoring of molecules is hybrid in the synthetic film (homeotropic anchoring close the air interface vs. planar anchoring close to the glass substrate) and it is planar close to the waxexocuticle and the endocuticle-epidermis interfaces. As a consequence, lines in the fingerprint texture connect perpendicularly to the air interface and in parallel to the glass interface in the synthetic film whereas they remain parallel to both interfaces in the cuticle. (iv) The synthetic film presents no pitch gradient when a pitch gradient from visible to NIR spectrum is present in the cuticle.

By investigating the light transmission of oligomer films, the wavelength-tunable microlens properties of polygons [75] and the role of the microlens size on the intensity and the focal length [76] have been demonstrated. Here we supplement these studies, focused on 
transmission, with the reflective properties to draw comparisons with the behavior found in $C$. gloriosa cuticle (Figure 4). Figure 9 shows the reflection maps for five wavelength ranges from blue to red. The microscope was focused onto the surface, i.e. the air-LC interface. The main result is that the minimum intensity is located at the center of synthetic polygons for all ranges, whereas a bright central spot was allotted to the polygon center in C. gloriosa cuticle. Reflection behaviors are thus antagonistic, as a consequence of the basic difference in the orientation of cholesteric pseudo-layers: convex in the oligomer film vs. concave in the cuticle. Concave micromirrors must therefore be targeted under the strategy of fabrication of biomimetic optical components.

(a)

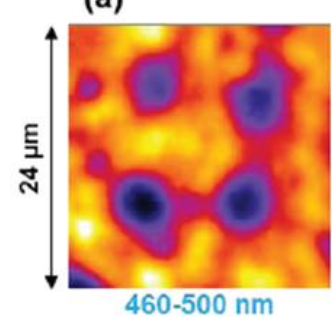

(b)

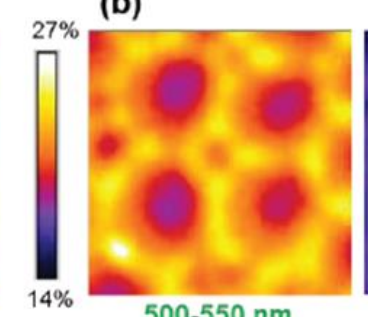

(c)

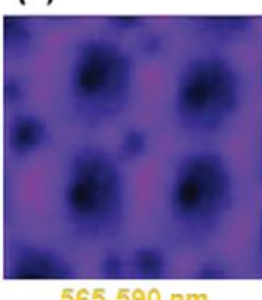

$565-590 \mathrm{~nm}$ (d)

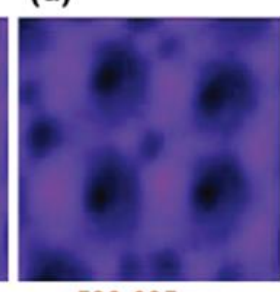

$590-625 \mathrm{~nm}$ (e)

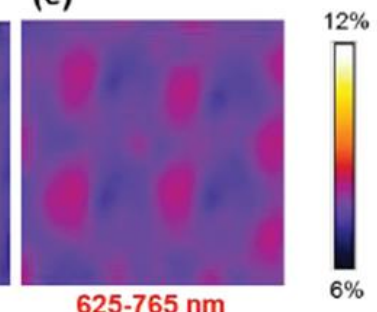

Fig. 9. Mapping of reflected intensity of polygonal texture from a synthetic oligomer film at the focus plane and for five wavelengths of the incident light. The bar scale [14\%; $27 \%]$ for the $[460 ; 500] \mathrm{nm}$ range is different from the one used for the other ranges for display purposes.

\section{Potential applications}

The reflection properties of the polygon arrays in the green stripes of $C$. gloriosa cuticles may serve as an inspiration for the fabrication of wavelength-tunable micromirrors. Each micromirror could serve as a wavelength-selective spatial light modulator, optimized for 
small form-factor applications and with highly flexible light patterns. Such micromirrors are desirable for fiber optics or optical switching [77-79], where micromirror technology will be essential for increasing the speed of communication. For example, when information needs to be re-routed to a personal computer. In an optical network, the transmission process is as follows: the switching station converts the incoming beam into a digital signal, sends it to the computer, then converts it back into a light beam. This task would become much easier if, instead of having to convert the signal twice, the signal may be focused onto a micromirror, automatically sending it to another fibre which is connected to the correct destination. By utilizing many of these micro-mirrors in sequence, the incoming signals can be re-routed to their destination without ever having to be converted into a digital signal, saving considerable time, and producing a higher network data transmission speed. This type of optical packet switching and routing technologies promises to provide a more efficient source of power and footprint scaling with increased router capacity.

\section{Conclusions and summary}

With its green stripes, Chrysina gloriosa simultaneously realizes the selective reflection of multiple wavelength ranges at normal incidence and the generation of diffusive reflections at a wide angular range. These seemingly conflicting requirements are fulfilled by combining, on a curved surface, appropriate regions of regularity and irregularity at different length scales: regularity with a set of polygonal cells, including a maximized fill factor, and a continuous pitch gradient inside an individual cell; irregularity with the tessellated texture and a non-monotonic orientation of the helicoidal axis inside the exocuticular part of an individual cell, forming a concave micro-mirror. In summary, the elaborate structure of $C$. gloriosa 
cuticles displays several optical phenomena: (1) the green stripe serves as a wavelengthselective (green) optical diffuser due to the set of polygons arranged on a curved surface; (2) the green stripe is a wavelength-selective mirror with, strikingly, reflection domains that may sometimes be delimited with net frontiers, whereas the cholesteric structure is regular and continuous from domain to domain; (3) the silver stripe plays the role of a flat metallic reflector operating over the visible spectrum and into the NIR spectrum; (4) the endocuticular part of both stripes are characterized by a broad reflection in the NIR-IR spectrum due to a graded-pitch CLC structure with no tessellated texture.

Previous literature has inferred that the polygonal cells of Chrysina gloriosa were structurally and optically analogous to the focal conic domains formed spontaneously on the free surface of a CLC film, on the basis of similarities between optical textures. It has been possible to correct this inaccurate hypothesis by addressing the topic with confocal microscopy and spectrophotometry, scanning and transmission electron microscopy, and numerical simulations. The main conclusion on this issue is that the cuticle has concave cells whereas the artificial films have convex cells.

We hypothesized several functions: Conspecific or intra-species communication: the green stripe displays information (color, polarization) in the visible spectrum and NIR spectrum; the wavelength-sensitivity of the reflection pattern, occurring essentially in the visible spectrum, may convey this information by being related to the spectral sensitivity of eyes of C. gloriosa conspecifics (and predators). Thermoregulation: NIR reflector may regulate temperature. Camouflage against diurnal predators (green diffuse reflection) or nocturnal predators capable of detecting IR light (since many green insects show a high NIR reflectance close to that of their habitat foliage); in addition, the shiny surface would mirror the green color of its 
environment and, during the dry season, the beetle could hide among the same leaves when they are brown. Survival: the bright glare from silver stripes might temporarily blind a potential predator, enabling $C$. gloriosa beetles to escape. Navigation if it is proved that a crepuscular and nocturnal insect like C. gloriosa use NIR or IR wavelengths for such a purpose. Studying biological structures such as the tessellated structure of the C. gloriosa cuticle at the nanometer and micrometer scales may thus provide valuable insight into how such phenomena could be exploited in the living world.

The present contribution may learn about the fabrication and design of photonic devices. The light reflection by $C$. gloriosa cuticles, with a variety of wavelengths and spatial patterns, may inspire the fabrication of wavelength-specific micromirrors and photonic crystals.

\section{Acknowledgements}

We are grateful to Dr. E. Hanelt from Wacker-Chemie GmbH (Munich, Germany) for providing us with CLC oligomers. We acknowledge Mr. C. Deshayes for his technical assistance in SEM investigations.

\section{References}

[1] A. C. Neville, Biology of the Arthropod Cuticle, Springer-Verlag, Berlin, Germany 1975.

[2] J. F. V. Vincent, U. G. K. Wegst, Design and mechanical properties of insect cuticle, Arthr. Struct. Dev. 33 (2004) 187-199. 
[3] C. Sanchez, H. Arribart, M. M. Giraud-Guille, Biomimetism and bioinspiration as tools for the design of innovative materials and systems, Nature Mater. 4 (2005) 277-288.

[4] S. Berthier, Iridescences, Springer, New York 2007.

[5] G. J. Blomquist, A.-G. Bagnères (Eds.), Insect hydrocarbons: Biology, Biochemistry, and Chemical Ecology, Cambridge University Press, Cambridge, UK 2010.

[6] L. Wang, Q. Li, Stimuli-Directing Self-Organized 3D Liquid-Crystalline Nanostructures: From Materials Design to Photonic Applications, Adv. Funct. Mat. 26 (2016) 10-28.

[7] N. Guarín-Zapata, J. Gomez, N. Yaraghi, D. Kisailus, P. D. Zavattieri, Shear wave filtering in naturally-occurring Bouligand structures, Acta Biomater. 23 (2015) 11-20.

[8] L.K. Grunenfelder, N. Suksangpanya, C. Salinas, G. Milliron, N. Yaraghi, S. Herrera, K. Evans-Lutterodt, S.R. Nutt, P. Zavattieri, D. Kisailus, Bio-inspired impact-resistant composites, Acta Biomater. 10 (2014) 3997-4008.

[9] X. Wu, A. Erbe, D. Raabe, H.-O. Fabritius, Extreme Optical Properties Tuned Through Phase Substitution in a Structurally Optimized Biological Photonic Polycrystal, Adv. Funct. Mat. 23 (2013) 3615-3620.

[10] D. Klocke, H. Schmitz, Material properties of photomechanical infrared receptors in pyrophilous Melanophila beetles and Aradus bugs, Acta Biomater. 8 (2012) 3392-3399.

[11] A. R. Parker, H. E. Townley, Biomimetics of photonic nanostructures. Nature Nanotech. 2 (2007) 347-353.

[12] A. C. Neville, S. Caveney, Scarabaeid Beetle Exocuticle as an Optical Analogue of Cholesteric Liquid Crystals, Biol. Rev. 44 (1969) 531-562. 
[13] H. Kelker, R. Hatz, Handbook of Liquid Crystals, Verlag Chemie, Weinheim, Germany 1980, pp. 293-337.

[14] V. A. Belyakov, V. E. Dmitrienko, Optics of chiral liquid crystals, Sov. Sci. Rev. A Phys. 13 (1989) 1.

[15] A. E. Seago, P. Brady, J.-P. Vigneron,T. D. Schultz, Gold bugs and beyond: a review of iridescence and structural colour mechanisms in beetles (Coleoptera), J. R. Soc. Interface 5 (2009) S165-S184.

[16] A. C. Neville, Biology of fibrous composites, Cambridge University Press, Cambridge, UK 1993.

[17] T. Lenau, M. Barfoed, Colours and Metallic Sheen in Beetle Shells-A Biomimetic Search for Material Structuring Principles Causing Light Interference, Adv. Eng. Mat. 10 (2008) 299-314.

[18] M. Srinivasarao, M. Crne, V. Sharma, J. O. Park, Scarab Beetle Iridescence, in: Yearbook of Science and Technology 2011, McGraw-Hill, US 2011.

[19] H. Arwin, R. Magnusson, J. Landin, K. Järrendahl, Chirality-induced polarization effects in the cuticle of scarab beetles: 100 years after Michelson, Phil. Mag. 92 (2012) 15831599.

[20] Z. Shen, H. Chen, L. Wu, in: L. Wu, J. Baghdachi (Eds.), Functional Polymer Coatings: Principles, Methods, and Applications, John Wiley \& Sons, Hoboken, NJ 2015, Ch. 9. 
[21] L. de Silva, I. Hodkinson, P. Murray, Q. H. Wu, M. Arnold, J. Leader, A. McNaughton, Natural and Nanoengineered Chiral Reflectors: Structural Color of Manuka Beetles and Titania Coatings, Electromagnetics 25 (2005) 391-408.

[22] K. Buhl, Z. Roth, P. Srinivasan, R. Rumpf, E. Johnson, Biologically inspired optics: analog semiconductor model of the beetle exoskeleton, Proc. of SPIE 7057 (2008) 1-8.

[23] S. A. Jewell, P. Vukusic, N. W. Roberts, Circularly polarized colour reflection from helicoidal structures in the beetle Plusiotis boucardi, N. J. of Phys. 9 (2007) 1-10.

[24] A. Crowe, Which New Zealand Insect?, Penguin, NZ 2002.

[25] F. Liu, H. Yin, B. Dong, Y. Qing, L. Zhao, S. Meyer, X. Liu, J. Zi, B. Chen, Inconspicuous structural coloration in the elytra of beetles Chlorophila obscuripennis (Coleoptera), Phys. Rev. E 77 (2008) 012901.

[26] T. D. Schultz, M. A. Rankin, The Ultrastructure of the Epicuticular Interference Reflectors of Tiger Beetles (Cicindela), J. Exp. Biol. 117 (1985) 87-110.

[27] J. P. Vigneron, M. Ouedraogo, J.-F. Colomer, M. Rassart, Spectral sideband produced by a hemispherical concave multilayer on the African shield-bug Calidea panaethiopica (Scutelleridae), Phys. Rev. E 79 (2009) 021907.

[28] D. K. Stavenga, B. D. Wilts, H. L. Leertouwer, T. Hariyama, Polarized iridescence of the multilayered elytra of the Japanese jewel beetle Chrysochroa fulgidissima, Phil. Trans. B 366 (2011) 709-723.

[29] M. Hernández-Jiménez, D. E. Azofeifa, E. Libby, C. Barboza-Aguilar, Á. Solís, L. Arce-Marenco, I. García-Aguilar, A. Hernández, W. E. Vargas, Qualitative correlation 
between structural chirality through the cuticle of Chrysina aurigans scarabs and left-handed circular polarization of the reflected light, Opt. Mat. Expr. 4 (2014) 2632.

[30] D. Wilts, H. M. Whitney, B. J. Glover, U. Steiner, S. Vignolini, Natural helicoidal structures: Morphology, self-assembly and optical properties, Mat. Today: Proc. 1S (2014) $177-185$.

[31] H. Goldstein, Polarization properties of Scarabaeidae, Appl. Optics 45 (2006) 79447950.

[32] R. Hegedüs. G. Szél, G. Horváth, Imaging polarimetry of the circularly polarizing cuticle of scarab beetles (Coleoptera: Rutelidae, Cetoniidae), Vis. Res. 46 (2006) 2786-2797.

[33] E. Azofeifa, M. Hernandez-Jimenez, E. Libby, A. Solis, C. Barboza-Aguilar,W. E. Vargas, A quantitative assessment approach of feasible optical mechanisms contributing to structural color of golden-like Chrysina aurigans scarab beetles, J. Quant. Spectr. Rad. Transf. 160 (2015) 63-74.

[34] W. E. Vargas, M. Hernandez-Jimenez, E. Libby, D. E. Azofeifa, A. Solis, C. BarbozaAguilar, Broadening of effective photonic band gaps in biological chiral structures: From intrinsic narrow band gaps to broad band reflection spectra, Europhys. Lett. 111 (2015) 64001.

[35] B. Thomas, A. Seago and D. C. Robacker, Reflections on golden scarabs, Amer. Entomol. 53 (2007) 224-230.

[36] A. Pace, Cholesteric liquid crystal-like structure of the cuticle of Plusiotis gloriosa, Science 176 (1972) 678-680. 
[37] Y. Bouligand, Sur l'existence de «pseudomorphoses cholestériques» chez divers organismes vivants, J. Phys. Colloq. 30 (1969) C4-90.

[38] V. Sharma, M. Crne, J. O. Park, M. Srinivasarao, Structural origin of circularly polarized iridescence in jeweled beetles, Science 325 (2009) 449-451.

[39] L. Fernandez del Rio, A. Arwin, K. Järrendahl, Polarizing properties and structural characteristics of the cuticle of the scarab beetle Chrysina gloriosa, Thin Solid Films 571 (2014) 410-415.

[40] L. Fernandez del Rio, A. Arwin, K. Järrendahl, Polarization of light reflected from Chrysina gloriosa under various illuminations, Mat. Today: Proc. 1S (2014) 172-176.

[41] J. Pierron, A. Boudet, P. Sopena, M. Mitov, P. Sixou, Cholesteric textures observed by transmission electron microscopy in diffraction contrast, Liq. Cryst. 19 (1995) 257-267.

[42] A. Boudet, C. Binet, M. Mitov, C. Bourgerette, E. Boucher, Eur. Phys. J. E 2000, 2, 247.

[43] A. Boudet, M. Mitov, C. Bourgerette, T. Ondarçuhu, R. Coratger, Glassy cholesteric structure: thickness variation induced by electron radiation in transmission electron microscopy investigated by atomic force microscopy, Ultramicroscopy 88 (2001) 219-229.

[44] F. Oskooi, D. Roundy, M. Ibanescu, P. Bermel, J. D. Joannopoulos, S. G. Johnson, MEEP: A flexible free-software package for electromagnetic simulations by the FDTD method, Comp. Phys. Comm. 181 (2010) 687-702.

[45] D. K. Hwang, A. D. Rey, Computational modeling of the propagation of light through liquid crystals containing twist disclinations based on the finite-difference time-domain method, Appl. Optics 44 (2005) 4513-4522. 
[46] O. F. Aguilar Gutierrez, A. D. Rey, Structure characterisation method for ideal and nonideal twisted plywoods, Soft Matter 10 (2014) 9446-9453.

[47] O. F. Aguilar Gutierrez, A. D. Rey, Chiral graded structures in biological plywoods and in the beetle cuticle, Colloids Interface Sci. Commun. 3 (2014) 18-22.

[48] S. Caveney, Cuticle reflectivity and optical activity in scarab beetles: the role of uric acid, Proc. Roy. Soc. London. Series B, Biol. Sci. 178 (1971) 205-225.

[49] D. Raabe, C. Sachs, P. Romano, The crustacean exoskeleton as an example of a structurally and mechanically graded biological nanocomposite material, Acta Mater. 53 (2005) 4281-4292.

[50] The term "pseudo-layers" is used instead of layers because the CLC structure is not a layered system. The CLC structure is often drawn as a stack of layers with an orientational order of molecules in each plane and a rotation by a constant angle of each plane with respect to its neighbors. However this representation is only a guide for the observer and these layers have no physical basis. When the CLC structure is modeled as a layered system, each "layer" behaves like a uniaxial anisotropic medium with the slow axis parallel to the rod-like molecules and the fast axis perpendicular to them. The two axes twist regularly and without discontinuity from "layer" to "layer". When light propagates through a CLC in the Bragg regime, the medium behaves like a multilayer system, which produces interferential colors.

[51] M. Mitov, Cholesteric liquid crystals with a broad light reflection band, Adv. Mater. 24 (2012) 6260-6276.

[52] T. R. Brosius, L. G. Higley, Behavioral niche partitioning in a sympatric tiger beetle assemblage and implications for the endangered Salt Creek tiger beetle, PeerJ 1 (2013) e169. 
[53] J. Teyssier, S. V. Saenko, D. van der Marel, M. C. Milinkovitch, Photonic crystals cause active colour change in chameleons, Nature Comm. 6 (2015) 6:6368.

[54] S. Caveney, Juvenile hormone and wound modelling of Tenebrio cuticle architecture, J. Insect Physiol. 16 (1970) 1087-1107.

[55] A. C. Neville, Biology of the Arthropod Cuticle, Springer-Verlag, Berlin, Germany 1975 , p. 8.

[56] H.E. Hinton, Some recent work on the colours of insects and their likely significance, Proc. \& Trans. Brit. Entomol. Soc. 6 (1973) 43-54.

[57] N. Young, Notes on the Habits of Plusiotis gloriosa Le conte (Scarabaeidae), Coleop.Bull. 11 (1957) 67-70.

[58] M. Mielewczik, F. Liebisch, A. Walter, H. Greven, Near-infrared (NIR)-reflectance in insects-Phenetic studies of 181 species, Entomologie Heute 24 (2012) 183-215.

[59] J. T. Lin, C. Y. Wu, A comparative-study on the color-vision of 4 coleopteran insects, Bull. Inst. Zool. Acad. Sin. 31 (1992) 81-88.

[60] A. D. Briscoe, L. Chittka, The evolution of color vision in insects, Annu. Rev. Entomology 46 (2001) 471-510.

[61] M. Dacke, P. Nordström, C. H. Scholtz, E. J. Warrant, A specialized dorsal rim area for polarized light detection in the compound eye of the scarab beetle Pachysoma striatum, J. Comp. Physiol. A 188 (2002) 211-216.

[62] E. Libby, D. E. Azofeifa, M. Hernández-Jiménez, C. Barboza-Aguilar, A. Solís, I. García-Aguilar, L. Arce-Marenco, A. Hernández, W. E. Vargas, Light reflection by the 
cuticle of C. aurigans scarabs: a biological broadband reflector of left handed circularly polarized light, J. Opt. 16 (2014) 082001.

[63] Y. Bouligand, Recherches sur les textures des états mésomorphes: Les champs polygonaux dans les cholestériques, J. Phys. 33 (1972) 715-736.

[64] T. J. Bunning, D. L. Vezie, P. F. Lloyd, P. D. Haaland, E. L. Thomas, W. W. Adams, Cholesteric liquid crystals: Image contrast in the TEM, Liq. Cryst. 16 (1994) 769-781.

[65] R. Meister, H. Dumoulin, M.-A. Hallé, P. Pieranski, The anchoring of a cholesteric liquid crystal at the free surface, J. Phys. II France 6 (1996) 827-844.

[66] R. Meister, M.-A. Hallé, H. Dumoulin, P. Pieranski, Structure of the cholesteric focal conic domains at the free surface, Phys. Rev. E 54 (1996) 3771.

[67] G. Agez, R. Bitar, M. Mitov, Color selectivity lent to a cholesteric liquid crystal by monitoring interface-induced deformations, Soft Matter 7 (2011) 2841-2847.

[68] R. Bitar, G. Agez, M. Mitov, Cholesteric liquid crystal self-organization of gold nanoparticles, Soft Matter 7 (2011) 8198-8206.

[69] A. Bobrovsky, K. Mochalov, A. Chistyakov, V. Oleinikov, V. Shibaev, Features of Double-Spiral 'Valley-Hills' Surface Topography Formation in Photochromic Cholesteric Oligomer-Based Films and Their Changes Under Polarized Light Action, Macromol. Chem. Phys. 213 (2012) 2639-2646.

[70] A. Bobrovsky, O. Sinitsyna, A. Abramchuk, I. Yaminsky, and V. Shibaev, Atomic force microscopy study of surface topography of films of cholesteric oligomer-and polymer-based mixtures with photovariable helix pitch, Phys. Rev. E 87 (2013) 012503. 
[71] O. V. Sinitsyna, A. Bobrovsky, I. Yaminsky, V. Shibaev, Peculiarities and mechanism of surface topography changes in photochromic cholesteric oligomer-based films, Colloid Polym. Sci. 292 (2014) 1567-1575.

[72] A. Bobrovsky, K. Mochalov, A. Chistyakov, V. Oleinikov, V. Shibaev, AFM study of laser-induced crater formation in films of azobenzene-containing photochromic nematic polymer and cholesteric mixture, J. Photochem. Photobio. A: Chem. 275 (2014) 30-36.

[73] O. Sinitsyna, A. Bobrovsky, G. Meshkov, I. Yaminsky, V. Shibaev, Surface Relief Changes in Cholesteric Cyclosiloxane Oligomer Films at Different Temperatures, J. Phys. Chem. B 119 (2015) 12708-12713.

[74] G. Agez, M. Mitov, Cholesteric liquid crystalline materials with a dual circularly polarized light reflection band fixed at room temperature, J. Phys. Chem. B 115 (2011) 64216426.

[75] C. Bayon, G. Agez, M. Mitov, Wavelength-tunable light shaping with cholesteric liquid crystal microlenses, Lab Chip 14 (2014) 2063-2071.

[76] C. Bayon, G. Agez, M. Mitov, Size-effect of oligomeric cholesteric liquid-crystal microlenses on the optical specifications, Optics Lett. 40 (2015) 4763-4766.

[77] M. Fabert, A. Desfarges-Berthelemot, V. Kermene, A. Crunteanu, Temporal synchronization and spectral combining of pulses from fiber lasers Q-switched by independent MEMS micro-mirrors, Optics Expr. 20 (2012) 22895-22901.

[78] W. Shin, Y. L. Lee, B. A. Yu, Y. C. Noh, T. J. Ahn, Wavelength-tunable thulium-doped single mode fiber laser based on the digitally programmable micro-mirror array, Opt. Fiber Tech. 19 (2013) 304-308. 
Accepted version in: Acta Biomaterialia 2017, 48, 357-367.

[79] C.-C. Huang, H. Jiang, Bio-inspired wide-angle broad-spectrum cylindrical lens based on reflections from micro-mirror array on a cylindrical elastomeric membrane, Micromachines 5 (2014) 373-384. 